\title{
(040-041) Two proposals on certain cases of effective publication
}

\section{Sennikov, Alexander Nikolaevich}

2015-05

Sennikov , A N 2015 , ' (040-041) Two proposals on certain cases of effective publication ' , Taxon, vol. 64 , no. 2 , pp. 393-393 . https://doi.org/10.12705/642.14

http://hdl.handle.net/10138/155205

https://doi.org/10.12705/642.14

acceptedVersion

Downloaded from Helda, University of Helsinki institutional repository.

This is an electronic reprint of the original article.

This reprint may differ from the original in pagination and typographic detail.

Please cite the original version. 


\title{
(040-041) Two proposals on certain cases of effective publication
}

\author{
Alexander N. Sennikov \\ Botanical Museum, Finnish Museum of Natural History, University of Helsinki, Unioninkatu 44, P.O. Box 7, 00014 Helsinki, Finland; \\ and Herbarium, Komarov Botanical Institute of Russian Academy of Sciences, Prof. Popov str. 2, 197376 St. Petersburg, Russia; \\ alexander.sennikov@helsinki.fi
}

Dol http://dx.doi.org/10.12705/642.14

\section{(040) Add a new Note to Art. 30.3 after Note 2:}

"Note 3. Electronic supplements and appendices issued separately in Portable Document Format (PDF) and linked to an online publication that complies with provisions of Art. 29.1 are treated as part of that publication."

This new note aims to clarify the status of electronic appendices and supplements, which are commonly used to deposit those parts of the content that are considered too technical or space consuming to be included into the main part of the publication. If such appendices and supplements contain checklists and lists of specimens, possibly with nomenclatural novelties or as parts of protologues of names published in the main publication, they are treated as effectively published if issued in PDF and linked with the main publication in an unambiguous way.

\section{(041) Add a new Article and a new Example after Art. 30.1:}

“30.1bis. Distribution of printed matter does not constitute effective publication if there is direct evidence within the work that it was not intended for effective publication."

"Ex. 1bis. A summary of the dissertation by Krassovskaya, "The genus Rubus L. (Rosaceae) in East Europe and the Caucasus", defended in 2002, was printed as a booklet lacking an ISBN but with a statement of the name of the publisher and the printer. Article 30.8 notwithstanding, names of new taxa and new combinations included in that work, although accepted by the author and accompanied with Latin descriptions and type statements, or with full and direct references to basionyms, were not effectively published because the title page of that work bears a statement "printed as manuscript"."

This new article is proposed to treat the ephemeral printed matter (primarily booklets) that is published and distributed, although by registered publishers and printing houses, on the same right as duplicated manuscripts. Such are, e.g., summaries of dissertations defended in the Soviet Union and the countries that inherited the Soviet system of academic science, university lectures issued separately, and lists of desiderata published in the past by herbarium exchange societies in the Nordic countries. Printed booklets of this kind were not intended for publication of new scientific content; to denote provisional character of such publications, they bore a statement which may be translated as "printed as manuscript" or "on the rights of manuscript", which was usually printed in the upper right corner of the title page. 